\title{
La imagen de China en la literatura del exilio y la configuración de un paisaje cultural
}

\author{
The image of China in the literature of exile \\ and the configuration of a cultural landscape
}

\section{David García Ponce}

Universidad de Barcelona. davidgponce@gmail.com

Recibido: 30/04/2018. Aceptado: 26/06/2018

Resumen: El artículo estudia la imagen literaria de China en la literatura del exilio español, a través de las obras de tres autores invitados por el gobierno chino: Sonríe China (1958) de M. ${ }^{a}$ Teresa León y Rafael Alberti y Andanzas por la nueva China (2017) de César M. Arconada. Estos autores, destacados componentes de la Edad de Plata de la literatura española, narran sus viajes por la China de Mao Zedong tras la Revolución Comunista. Sus experiencias basculan entre la fascinación y la disidencia. Con este material, analizamos los elementos comunes y los rasgos específicos de cada uno de los autores que junto con el análisis de los cambios acaecidos en China permiten configurar un paisaje cultural y una valoración del mismo.

Palabras clave: literatura de viajes; dictadura; exilio; China; paisajes culturales.

\begin{abstract}
The article studies the literary image of China, in the Spanish exile literature, through the novels of three authors invited by the Chinese government: Sonrie China

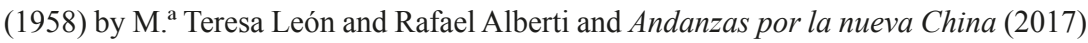
by César M. Arconada. These writers, who were prominent authors of the Edad de Plata (Silver Age) of Spanish literature, narrate the journeys they made to the new China of Mao Zedong after the Communist Revolution. Their experiences present a specific rhetoric that revolves around fascination and dissidence. With this information, common elements and specific features of each author are analysed, together with the study of changes that have taken place in China. All these factors allow us the configuration of a cultural landscape and an appreciation of it.
\end{abstract}

Keywords: travel literature; dictatorship; exile; China; cultural landscapes.

》 García Ponce, David. 2018. "La imagen de China en la literatura del exilio y la configuración de un paisaje cultural”. Quaderns de Filologia: Estudis Literaris XXIII: 157-180. doi: 10.7203/qdfed.23.13468 



\section{La brecha intelectual de los cincuenta y la literatura de viajes}

La literatura española de mediados del siglo XX se sitúa en un mapa disperso. Por un lado, están los escritores que permanecen en el país bajo la Dictadura y, por otro, la pléyade de escritores que se ven obligados a abandonar España tras el final de la contienda bélica y que se instalan en Europa, Hispanoamérica y, en menor medida, la Unión Soviética. Entre las obras de los autores que permanecen en España y la de los exiliados existen diferencias significativas tanto en las influencias artísticas como en las literarias y, en otro orden de factores, una literatura de viajes es también diferente ${ }^{1}$.

En realidad, en las décadas previas a la contienda bélica, la literatura española vive un proceso de renovación. Los jóvenes del 27, la mayoría nacidos a principios del siglo XX, formados con autores internacionales e influenciados por las teorías de Ortega y Gasset, defienden el advenimiento de la II República y con ello impulsan proyectos de renovación intelectual. Vivieron el periodo de la Edad de Plata $^{2}$ de la literatura española y con ellos se forja un arte de vanguardia que busca otros horizontes: se traducen nuevos autores que componen un nuevo humanismo a la vez que crean un ideario intelectual progresista.

En esta nómina de exiliados figuran los jóvenes protagonistas del panorama intelectual de los años treinta. Aquellos que comenzaron su andadura literaria en los años en que las vanguardias renovaban la literatura española. Sin embargo, la guerra y, más tarde, la Dictadura

\footnotetext{
* El presente artículo se integra en la producción del proyecto internacional: "The Silk Road: development and research Institution" del grupo de investigación consolidado "Patrimonio y Artes Visuales en Europa, Asia y América" HUM068 del Sistema Científico de la Comunidad de Andalucía.

${ }^{1}$ En modo alguno, pretendemos analizar la década de los cincuenta como una generación literaria ni establecer una poética conjunta. Consideramos estos años como un periodo en el cual la literatura publicada en España ha experimentado una evolución desde el final de la guerra. Asimismo, los escritores del exilio cuentan con una producción sólida en los diferentes géneros literarios.

${ }^{2} \mathrm{La}$ Edad de Plata es un término empleado por la crítica para señalar el primer tercio del siglo XX. En este periodo, a semejanza de otras naciones europeas, "se aprecia un cambio enorme en el contexto general del país en la modernización de sus estructuras sociales y económicas, y también en las expectativas con respecto a la literatura y a la función de la literatura" (Mainer, 1981: 24). A este punto de inflexión hay que sumarle la renovación pedagógica y una producción fecunda de obras que organizan la vida cultural española hasta la Guerra Civil.
} 
anulan por completo cualquier proyecto de innovación literaria y silencian los ecos vanguardistas. La "España peregrina" de la causa antifascista y da voz a la memoria silenciada.

En este contexto, la literatura española del medio siglo cuenta con un escritor comprometido desde ambos frentes: los de dentro y los de fuera; residentes en España y exiliados que por medio de la composición literaria se posicionan políticamente. Este compromiso, en un lado y en otro, también está presente en la narrativa de viajes.

En los cincuenta encontramos los viajes nacionales, recogidos en crónicas de filiación realista, y los viajes narrados por los autores en el exilio $^{4}$. Estos buscan en este género el vehículo para canalizar el sentimiento de desorientación y desarraigo. Su objetivo no se limita a una reproducción fiel de los espacios, sino más bien tratan de incorporar una pincelada personal que le confiera vida propia a la composición literaria. El viaje, más allá de una crónica, es una experiencia personal.

\section{El viaje a China: el país de la seda}

Con la instauración de la Dictadura las relaciones con China quedaron limitadas a ciertos sectores de la izquierda española que compartían la ideología maoísta. La autarquía económica y el rechazo del bloque comunista abortaron cualquier proyecto de colaboración. Sin embargo, algunos autores exiliados tuvieron la oportunidad de viajar al país y relatar la transformación tras la Revolución Comunista. Para estudiar la relación entre algunos escritores exiliados y China, debemos remontarnos al primer tercio del siglo XX y partir desde Rusia.

En las tres primeras décadas del siglo XX, se traducen en España algunos escritores rusos decimonónicos y paralelamente también surge un apogeo de la literatura rusa y "un creciente prestigio del comunismo entre los intelectuales" (Taillot, 2013) a raíz de la Revolución de 1917. De igual modo, el intelectual establece un compromiso sociopolítico con la realidad del momento. En este sentido, un buen número de autores de la Edad de Plata encuentra en los escritores rusos un referente cultural. De esta manera, la coyuntura política en Rusia incita a sus

\footnotetext{
${ }^{3}$ Término acuñado por el escritor exiliado José Bergamín (1895-1983).

${ }^{4}$ Partimos de la tesis de que tanto los autores residentes en España como los del exilio tienen unos objetivos y preocupaciones comunes, por tanto, prescindimos de la divergencia entre literatura nacional y aquella escrita desde el exilio.
} 
autores a tratar temas que resultarán de interés en la intelectualidad española, tales como la cultura en las clases proletarias, los cambios en las estructuras económicas y sociales, etc.

La Guerra Civil radicaliza la posición política de los escritores contrarios al régimen y favorables a los cambios acaecidos en el bloque comunista. Motivo por el cual el Régimen los consideró como una amenaza para el poder, y, por tanto, muchos de ellos se ven obligados a abandonar su país. Los que fueron a Rusia encontrarán, según el poeta y ensayista Gil-Albert, "confianza, si no ciega sí bastante embriagadora" (Lechner, 1968: 120-121). En la nueva residencia, trasladan su discurso disidente al plano literario y combaten sus proyectos frustrados con un exilio fértil intelectualmente. De este modo, Rusia será el puente de contacto con la cultura China debido a las buenas relaciones entre ambos países a principios de los cincuenta.

Varios escritores visitaron China en los años posteriores a la Revolución Comunista de 1949. Con la incorporación de Mao al poder, el gobierno chino pretende transmitir un proyecto de bienestar y progreso a los otros países comunistas, así como a intelectuales afines a la ideología. Este es el caso de algunos escritores españoles que, por su militancia en partidos comunistas o por su vinculación con Rusia, reciben una invitación para visitar el país.

\section{Los viajes de M. ${ }^{\mathrm{a}}$ Teresa León, Rafael Alberti y César M. Arconada}

Entre la fecunda producción literaria de los escritores españoles exiliados, ocupan un lugar relevante Andanzas por la nueva China (2017) de César Muñoz Arconada y Sonrie China (1958) de María Teresa León y Rafael Alberti. El primero pasó los últimos veinticinco años de su vida exiliado en Rusia. Mientras que el matrimonio formado por Rafael Alberti y M. ${ }^{a}$ Teresa León visitaron en tres ocasiones la URSS ${ }^{5}$ durante la década de los treinta. Asimismo, en mayo de 1933 fundaron la revista Octubre, de clara filiación comunista, que afianzó, por un lado, las relaciones intelectuales entre Rusia y el gobierno republicano y, por otro,

\footnotetext{
${ }^{5}$ El primer viaje de Rafael Alberti y M. ${ }^{a}$ Teresa León fue en 1932 e hicieron dos estancias más en 1934 y 1937. Posteriormente, Alberti recibió en Moscú el premio Lenin en 1965 y en 1977 visitó el país por última vez.
} 
la concepción de la literatura como instrumento de lucha ideológica. En definitiva, Octubre, hasta su cierre en abril de 1934, difunde el modelo intelectual soviético. El propio Arconada participó en cuatro números de la revista.

Los primeros contactos entre estos escritores se remontan a los años treinta. En 1937 participaron en el II Congreso Internacional de Escritores para la Defensa de la Cultura celebrado en Barcelona, Madrid y Valencia. Asimismo, los Alberti mantienen encuentros con César M. Arconada y con su esposa María Canovas en sus visitas a Moscú. Los tres autores son paradigmas de intelectuales revolucionarios y desarrollan una literatura comprometida.

En 1957, Arconada y los Alberti reciben, por separado, una invitación de la Asociación de Escritores de la China para visitar el país y conocer las reformas que Mao estaba llevando a cabo. Con esta iniciativa, que formaba parte del programa de actividades de la Internacional Comunista, el gobierno chino pretendía extender una imagen de bienestar y progreso ante los intelectuales afines al régimen ${ }^{6}$.

Se trataba de un viaje organizado y coordinado por las autoridades del país. Se pedía a los invitados que aportasen en sus trabajos una imagen favorable del momento histórico y que omitiesen cualquier tipo de crítica que perjudicase la imagen de China. Los anfitriones españoles realizaron todo el viaje acompañados por un séquito que velaba por la organización correcta del viaje mientras contribuían a difundir una imagen propagandística de su país.

Las dos obras de estudio se enmarcan dentro del relato o literatura de viajes, ya que narran las vivencias e impresiones que reciben de los diferentes lugares que visitan, es decir:

Se asientan en los hechos, en la realidad, en los testimonios, en lo verificable. Lo ficcional no adquiere forma sustantiva en estos textos, sino más bien adjetiva. [...] las representaciones de objetos y personajes, que constituyen el núcleo de la descripción, asumen el protagonismo del relato (Alburquerque, 2011: 16).

Sobre esto último, Sofía Carrizo añade:

${ }^{6}$ Otros escritores invitados fueron Blas de Otero, Nicolás Guillén y Miguel Ángel Asturias. 
se trata de un discurso narrativo-descriptivo en el que predomina la función descriptiva como consecuencia del objeto final, que es la presentación del relato como un espectáculo imaginario, más importante que su desarrollo y su desenlace. [...] Debido a su inescindible estructura literario-documental, la configuración del material se organiza alrededor de núcleos del clímax que, en última instancia, responden a un principio de selección y jerarquización situado en el contexto histórico y que responde a expectativas y tensiones profundas de la sociedad a la que se dirigen (Carrizo Rueda, 1997: 28).

Tanto para los Alberti como para Arconada el viaje representa una experiencia personal; sus experiencias por el país suponen una dosis de optimismo, la respuesta a sus aspiraciones políticas y el cauce para escribir sobre sus recuerdos de España y el desacuerdo con el Franquismo.

\section{1. "QQue se abran todas las flores!””. M. ${ }^{a}$ Teresa León y Rafael Alberti en China}

M. ${ }^{\text {a }}$ Teresa León (1903-1988) y Rafael Alberti (1992-1999) se conocieron en 1929 y tres años más tarde contraen matrimonio. Ambos compartieron varios proyectos literarios. Ella nació en Logroño, estudió en la Institución Libre de Enseñanza y se licenció en Filosofía y Letras. Él era originario de El Puerto de Santa María (Cádiz). En su juventud se traslada a Madrid y entra en contacto con los vanguardistas. Alberti fue un miembro activo del grupo del 27, al cual M. ${ }^{a}$ Teresa León siempre

\footnotetext{
${ }^{7}$ Frase exclamativa de Sonríe China que da título a un poema de R. Alberti y a un texto de M. ${ }^{\text {a }}$ Teresa León (193-194). Las flores ya están presentes en el imaginario de los primeros poemas del poeta gaditano y contienen gran densidad metafórica: es el paisaje primaveral que el matrimonio encuentra en China. De igual forma, la flor simboliza la esperanza de un deseo de apertura desde un plano imaginario. En otro orden de cosas, hace alusión a la "Campaña de las cien flores": se trata de un periodo entre 1956 y 1957 en el cual Mao Zedong fomenta un debate entre intelectuales para conocer la opinión de estos acerca de los problemas políticos y económicos que aquejaban al país. Con esta iniciativa se pretendía fortalecer la estructura del Partido Comunista. Todo ello puso de relieve el descontento ante determinadas políticas sociales en la República Popular de China y con las actividades culturales de la Internacional Comunista. En 1957 Mao Zedong detuvo esta campaña. Este mismo año comenzó la persecución de intelectuales, disidentes y estudiantes y, en cierto modo, esta campaña hace tambalear la euforia revolucionaria de los años anteriores.
} 
estuvo vinculada. Según Torres Nebrera, cuando el matrimonio abandona España en marzo de 1939: "empezaba el peregrinaje, llevando consigo el compromiso de no olvidar nunca, de sobrevivir en los espacios de la memoria" (León, 1998: 13). Su actividad literaria durante el exilio fue intensa.

En 1957, el matrimonio acompañado por su hija Aitana emprende desde su residencia de Buenos Aires, un viaje que atravesarían el Atlántico y Europa y cuyo destino final sería China. Aunque los autores se sentían integrados en Argentina, les acompaña el sentimiento desarraigo propio del exilio:

¡Sipañá! [...] Aquel país resucitará de nuestros muertos y, desaparecidas las escorias de más de veinte años de amargura, una bondad nueva cubrirá los campos de mi patria (51).

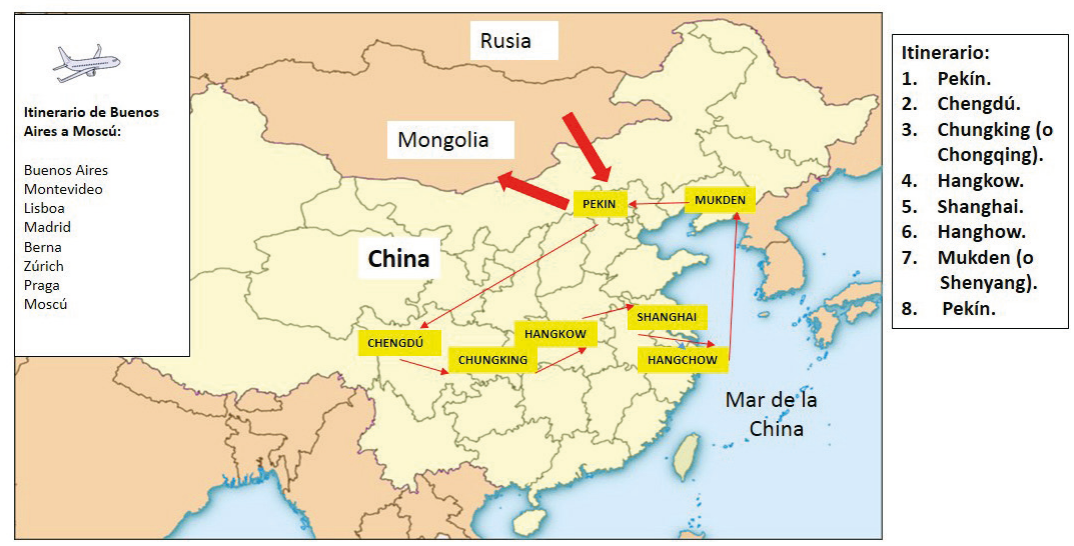

Fig. 1. Itinerario realizado por M. ${ }^{\mathrm{a}}$ Teresa León y Rafael Alberti en 1957, más tarde publicado en Sonríe China (1958). Mapa del autor.

El viaje a China coincide con una época de reconstrucción nacional y cambios en las estructuras sociales, económicas y políticas. A pesar de que 1957 es un año de inflexión, los Alberti vieron los cambios con buenos ojos, tal y como expresa M. Teresa León:

De esa cantera agrícola irán saliendo los obreros para incorporarse a las fábricas, y ese campo, tratado intensivamente como un jardín, recibirá 
los beneficios de haber creído que el socialismo puede apoyarse y florecer en un país agrícola (82).

Fruto de este viaje publican Sonrie China en 1958, en la editorial Jacobo Muchnik de Buenos Aires. Se trata de una obra escrita a cuatro manos, en la que la poesía de Rafael Alberti y la prosa de M. ${ }^{a}$ Teresa León funden una voz lírica de clara raigambre modernista, para narrar el viaje que, a grandes rasgos, recoge el poema de Alberti "Buenos Aires-Pekín" (7-12). Juntos recorren diferentes lugares de China: desde accidentes geográficos, escenarios de fiestas y tradiciones, pasando por ciudades como Chengdú, Chungking, Hangkow, Shangai, Hanghow y Munken ${ }^{8}$.

Sonríe China es una composición formada por texto e imágenes. La obra consta de tres partes correspondientes a etapas diferentes del viaje. Estas se dividen en epígrafes que relatan experiencias y observaciones de los lugares visitados. La prosa de M. ${ }^{a}$ Teresa León va acompañada, en algunos casos, por poemas de Rafael Alberti ${ }^{9}$ o, en otros, por ilustraciones del poeta gaditano de motivos orientales que reproducen el trabajo de los "pintores de tijera"

Todo el mensaje de la gracia candorosa del papel y la sabiduría de los siglos vienen a cuajarse en los ojos. El más viejo -difícil saber en China cuál es el más viejo- nos enseña los instrumentos de su trabajo: unas tijerillas, un redondel lleno de cera, cuchillitas diferentes para cortar, y papel blanco y papel rojo, sobre todo (108).

\footnotetext{
${ }^{8}$ Las dos obras que analizamos en el artículo se escribieron durante el periodo de reforma de la escritura tradicional a la simplificada. Una iniciativa promovida por la República Popular en 1955. Es probable que los autores españoles emplearan los topónimos en su versión tradicional o guiados por el oído. Se ha respetado la forma empleada por ellos para el texto de este artículo y para los mapas.

${ }^{9}$ Los poemas de Alberti de su viaje a China se pueden encontrar en el capítulo de $L a$ primavera de los Pueblos en las Obras Completas cuya primera edición se publicó en 1962 por la Editorial Losada de Argentina.

${ }^{10}$ Rafael Alberti comenzó a pintar con una edad temprana. Su primera exposición la organizó con el pintor onubense Daniel Vázquez Díaz en 1920, en el Ateneo de Madrid. Hasta su viaje a China se había inspirado en el impresionismo. Una vez allí, visita una cooperativa artesana de Hangkow y por primera vez conoce el empleo de la técnica de pintura de tijera (León, 1958: 107).
} 
La admiración del poeta gaditano por la pintura china le lleva a dedicar un poema al pintor Chi Pai-Shih en el cual demuestra sensibilidad por la pintura oriental:

Y así sueñes, pintor, ya en los confines

del jardín de la paz de tu pintura, junto a tu pueblo, que en la paz madura como el árbol mejor de tus jardines (181).

También M. ${ }^{\text {a }}$ Teresa León hace referencia a la pintura china:

En China no se aprende a escribir, se aprende a pintar con el pincel que dibuja los signos. [...] Los caracteres parecen guerreros, espadas, lluvias, techos, rejas, brazos, pies, llaves, juncos, flores. De ahí, a la pintura está el paso donde, el aguatinta se extiende por el trozo de seda o la lámina de papel, figurando el río, el árbol, la barquita, los montes, la laguna, el pescador. [...] Pero ellos no tienen ningún interés por la eternidad. Su pintura son libros de imágenes que se desarrollan y se miran. Así, al irlos desatando y al verlas deslizarse, las imágenes nos producen el asombro de lo fugaz, de lo que huye, y de lo que no tiene pretensiones de permanecer ante nuestra vista (101).

Toda la obra contiene numerosas referencias intertextuales en las que claramente se percibe el magisterio de la Edad de Plata. Así por ejemplo, la autora recuerda el viaje de Vicente Blasco Ibáñez ${ }^{11}$ a China en 1921, el cual considera muy diferente con respecto al suyo, ya que el autor valenciano "se mueve entre los signos de lástima y miedo, de inseguridad y de aprensión" (215). Asimismo, no faltan referencias clásicas, a alegorías bíblicas y a personajes de la literatura española como son el Cid Campeador y Platero, entre otros.

Se trata de una obra con contenido ideológico, pero sin descuidar los principios estéticos. Los Alberti, además de compartir unos ideales políticos, sienten una admiración por la cultura y la sociedad china.

\footnotetext{
${ }^{11}$ Vicente Blasco Ibáñez (1867-1928) publicó en 1925 La vuelta al mundo de un novelista, obra en la cual relata su viaje por tres continentes y su parada en Shanghai y Canton. El autor valenciano lleva a cabo una descripción personalizada y detallada de los paisajes urbanos y rurales e incluye las conversaciones mantenidas con residentes españoles. En su prosa demuestra una fascinación por China y contribuye a crear una imagen más precisa del país.
} 
Ambos siguen un criterio personal para seleccionar los apuntes sobre los paisajes, núcleos urbanos, relatos históricos y actividad productiva, tanto la fabril como la artesanal.

M. ${ }^{\text {a }}$ Teresa León se rige por unas pautas similares en todos los apartados. En todos ellos, observa el paisaje interrogando al propio sujeto sobre las sensaciones que experimenta. Después, parte de la observación de detalles minúsculos que relacionan cuestiones de índole diferente -historia, tradiciones, geografía etc.- para acabar con cuestiones generales del país. En ocasiones, emplea fórmulas reiterativas, pero sin perder por ello la cohesión textual. En algunos fragmentos se dirige al lector con un tono bucólico, mientras que en otros transmite alegría y júbilo. No obstante, tanto para el poeta como para la prosista, la admiración convive con el recuerdo y la añoranza de España, de tal manera que conectan los paisajes y las vivencias en China con otros propios de la península ibérica. Así, por ejemplo, algunas casas de campesinos le recuerdan "las 'glorias' de las casas rurales de la sierra de Burgos" (54) y la presencia de dos aves oscuras en el patio de un hotel le hace pensar en "el terror de las horas de España" (66). En realidad, la patria es una preocupación constante de tal manera que "el espacio literario es un espacio de recuerdo y de la recreación de la experiencia vivida" (Taillot, 2009: 36).

Si bien las descripciones responden a un criterio personal, por encima de todo, relatan los acontecimientos de la China Revolucionaria y los cambios que el país está experimentando:

Tantos fueron soldados y tantos fueron héroes de una sola bandera cuando la Larga Marcha ${ }^{12}$. Mas todos son los hijos del Primero de Octubre y a todos por igual su luz los condecora (38).

En el viaje no faltan alusiones a lugares singulares como, por ejemplo, la Muralla China: "La Gran Muralla se construye, con gritos roncos y tristes. / La luna y la Vía Láctea parecen bajas ante ella" (204). Sin embargo, Alberti construye sus propias imágenes para explicar la

\footnotetext{
${ }^{12}$ La Larga Marcha se considera uno de los hitos más importantes del Partido Comunista de China. Este apelativo se refiere al viaje que siguió el ejército del Partido Comunista por el interior del país entre los años 1934 y 1935, y que supuso la subida al poder de Mao Zedong.
} 
relevancia del monumento, de modo que marca una diferencia con los relatos tradicionales de viajeros del siglo XIX. Una vez más, el poeta demuestra una sensibilidad por el imaginario oriental que:

supone una conquista importante que viene a enriquecer muy positivamente la expresión del universo poético del autor de Marinero en tierra (Hernández, 1986: 154).

De su experiencia en China hace materia poética y crea un canal para expresar, en otra configuración espacial, el panorama triste pésimo de su país. Para Torres Nebrera, M. ${ }^{\mathrm{a}}$ Teresa León en Sonríe China tiene la siguiente visión:

otro pueblo que había sabido vencerse a sí mismo y encontrar la salida de esa férrea muralla que parecía ahogarlo durante siglos y siglos de opresión en su propio ritual de emperadores y hambre adornada de gusanos de seda (1992: 355).

Este crítico, especialista en la autora riojana, opina que su obra literaria es:

una narrativa $[\ldots]$ escrita fuera de España, pero con España muy dentro, asomando por todos los márgenes, colocándose por entre todas las líneas (Torres Nebrera: 367).

La autora se interesa especialmente por la vida en las ciudades y por la situación de la mujer, tanto el ama de casa como la obrera. Con respecto a lo primero, centra su atención en el crecimiento vertiginoso de las ciudades, un fenómeno que lo percibe desde la idea de progreso y evolución:

Son las descendientes de otras mujeres que fueron muy poco apreciados en la vida china $[\ldots]$ a las que se podía maltratar, abandonar, cancelar con ellas todos los compromisos. [...] Ahora ninguna mujer baja la vista. Las encontramos vestidas de pantalones, con su airecillo varonil, sin complejos, pisando decididas en sus tareas de soldado, enfermeras, de maestras, [...] Unas y otras son la entraña de la República Popular China (41-42). 
En cierto modo, el matrimonio alude a un tema frecuente en los autores del 27 como es el civitas hominum, fundamentado en una visión cosmopolita de la urbe y una mirada armónica de esta. Estos autores captan tanto la ciudad moderna y progresista como la tradicional.

M. Teresa León narra las mejoras conseguidas por el proletariado. En esta línea, analiza la situación de los estudios universitarios; las obras de ingeniería; los datos concretos sobre el índice de natalidad; las cifras con los índices de producción y las medidas de las reformas agrarias integradas en el Primer Plan Quinquenal: “... que harán de China, según Mao Tse Tung, dentro de cuarenta años, un país tan industrializado como cualquiera del mundo" (155). Alberti complementa la visión optimista con un poema titulado "Primavera en Chengtú" (50-51).

El interés por la vida en las fábricas que los organizadores querían mostrar en clave de éxito y la atención que la autora hace de la situación de la población femenina en el país, le lleva a describir minuciosamente las visitas a sederías, en concreto la de Chengtú. En este taller, las empleadas habían pasado de trabajar en un sistema de explotación a tener un sistema laboral más justo.

También Alberti siente interés por estos espacios y pinta un cuadro de un andamio de bambú con la técnica de pintura de tijera y dedica a esta actividad el poema "Los tejedores de Seda":

Hijos de $\operatorname{Han}^{13}$, los artesanos más prodigiosos del estilo, los que, la luz entra en las manos, la luz dibujan hilo a hilo.

Hijos de Han, los imperiales y ayer pacientes más oscuros: tejed hoy libres los reales sueños presentes y futuros. (57)

M. Teresa León evoca los orígenes remotos de la sericultura y analiza su evolución histórica y las nuevas técnicas de producción, de tal

\footnotetext{
${ }^{13}$ R. Alberti se refiere a la Dinastía Han que reinó en China desde el 206 a.C. hasta el 220 d.C. aproximadamente, y que coincide con un periodo de expansión territorial y fomento de las rutas comerciales, como es el caso de la Ruta de la Seda.
} 
modo que la autora rinde homenaje a la actividad artesanal y, a su vez, celebra el progreso industrial:

Ser tejedor de seda no es una improvisación, es una herencia. Se nace, se madura, se encanece y se muere tejedor. [...] Entre el rumor me entero de que las familias de tejedores agruparon sus telares, hicieron una cooperativa de producción y hoy están contentos. Un obrero gana hasta cuarenta yens mensuales, contra quince de antes. Antes no tenía una casa limpia, ni escuela en el barrio ni dispensario, ni hospital, ni los hombres podían envejecer a cubierto de enfermedades, ni podían enterrarse dignamente, ni leer un libro. La cooperativa está haciendo su capital (León, 1958: 55-56).

En el apartado "Serica", la autora recupera historias sobre los gusanos de seda y las relaciona con la importancia histórica de esta actividad en China y la relación propiciada con España:

Serica [...] no sería alcanzada hasta el siglo XVI, después de instalarse en 1567 los españoles en la isla de Filipinas. Pero del sedoso insecto las españolas íbamos pronto a recibir, más que ningún país de la tierra, una inesperada y graciosa envoltura: el mantón [de Manila]. (178)

M. Teresa León recoge el testimonio de la vida dentro de las recientes fábricas protoindustriales que supuestamente aportarán modernidad y bienestar. En ellas, la presencia femenina ocupa un nivel de ocupación alto, y es precisamente en los telares donde la escritora observa un reconocimiento del trabajo y una mejora de las condiciones laborales. Con ello, León observa la actividad desde una perspectiva poco frecuente hasta el momento, y que además contribuye a ampliar el conocimiento de la sericultura.

A pesar de ser un viaje con fines propagandísticos, los Alberti consiguen un resultado literario que supera en calidad a un registro panfletario. Ambos autores emplean alegatos biográficos y mantienen un doble cometido: la exaltación de la cultura china en todas sus facetas y el espacio dedicado al recuerdo de España que bascula entre consignas combativas a y un claro sentimiento de nostalgia.

Las impresiones del viaje concluyen con la metáfora de la sonrisa que da título a la obra y que es el símbolo del optimismo que transmiten los autores. En definitiva, de la obra late un deseo de paz para este pueblo y para el suyo: 
No se nos borrará jamás de los ojos la sonrisa de China. Cuidadosamente la llevaremos dentro hasta nuestro país del otro extremo del mundo, donde ya hemos vivido media existencia (224).

\subsection{El viaje de César M. Arconada: recorridos por China y recuerdos de Xibanya ${ }^{14}$}

Peor suerte tuvo Cesar Muñoz Arconada (1898-1964) con la publicación de Andanzas por la nueva China. En 1958, lo intenta en Rusia, pero las relaciones entre China y la Unión Soviética habían empeorado y consecuentemente el interés por difundir la cultura del país vecino. El manuscrito fue igualmente rechazado por la editorial Ebro ${ }^{15} \mathrm{y}$ en Buenos Aires por coincidir con la publicación de Sonríe China. Por estas razones, hasta el año 2017 no verá a la luz la publicación.

César Muñoz Arconada, novelista, ensayista, poeta, articulista y crítico musical, evoluciona desde los postulados vanguardistas hacia un marxismo ortodoxo al servicio del ideal republicano. Su obra plantea una evolución tanto ideológica como estética. Tras la derrota de la República, se traslada a Francia donde pasará un tiempo en un campo de concentración del que pudo salir gracias al Comité de Ayuda Francés. Más tarde, en lugar de optar como otros compatriotas por el exilio a Hispanoamérica, decide ir a Rusia donde se instaló hasta su muerte en 1964, sin retornar nunca a España.

Por encima de todo, Arconada es un escritor comprometido convencido del Marxismo y posicionado con el prosovietismo, que hace de la literatura un arma contra el olvido y, entre líneas, deja filtrar su posición ideológica. Hace de la literatura:

un instrumento para analizar la sociedad y contribuir a transformarla, al poner al descubierto los mecanismos que perpetuaban y hacían posible el mantenimiento de situaciones opresivas e injustas (Esteban y Santonja, 1988: 11).

\footnotetext{
${ }^{14}$ España en chino.

${ }^{15}$ Editorial del PCE instalada en París que consiguió publicar algunos libros censurados por la Dictadura.
} 
En Rusia contribuyó notablemente a la difusión de la literatura española, fue responsable de la revista Literatura soviética y llevó a cabo traducciones. En cierto modo, encontró en el exilio el medio adecuado para mantenerse vinculado con las letras españolas.

Según Gonzalo Santonja, el autor escribe bajo una doble condición: con la nostalgia de la patria abandonada y con su ideología comunista que queda claramente identificada (Arconada, 2017: XVII). Desde su entrada en China muestra un interés por el país:

Me figuro la nueva China como un río inmenso de limo fecundo y de aguas caudalosas. Y entonces me pregunto: ¿dónde están sus fuentes? Porque quiero ir a buscarlas... (5)

Los elementos naturales le sirven de metáfora para expresar el interés por un territorio de cuyo progreso evidente ya tiene noticias.
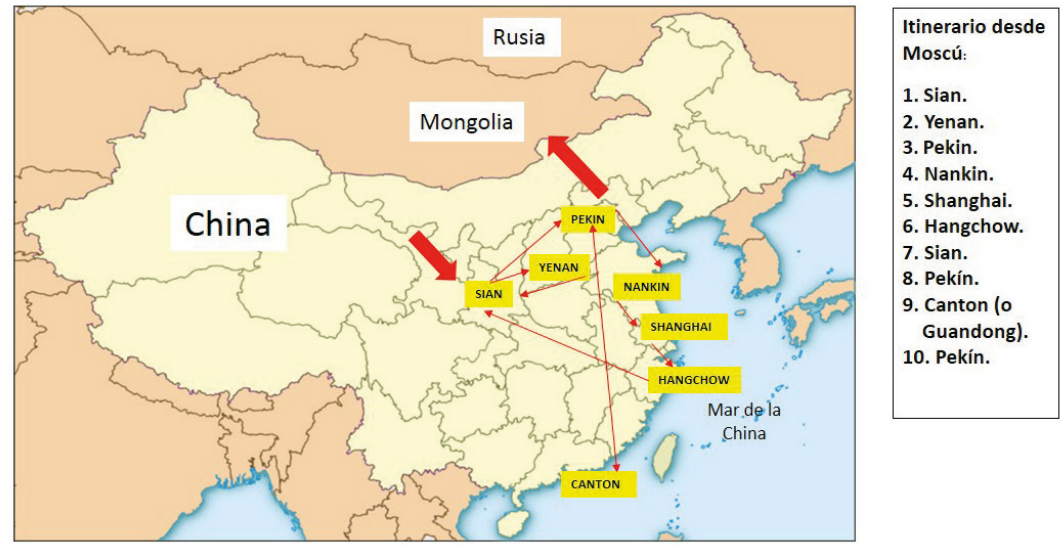

Fig. 2. Recorrido llevado a cabo por César M. Arconada en 1957, narrados en Andanzas por la nueva China (2017). Mapa del autor.

Arconada, como tantos otros autores exiliados, recurre a la cultura hispánica y a sus referentes literarios. Uno de ellos es Don Quijote de la Mancha de Miguel de Cervantes:

No es extraño que el Hidalgo manchego don Quijote viera gigantes en los molinos, cuando yo, menestral de Castilla, veo desde el tren proce- 
siones con estandartes remendados, como si pendones fuesen conducidos por la llanura de los mendigos (34).

También el autor palentino recurre con frecuencia a las lecturas de Miguel de Unamuno. Sin embargo, tanto en un caso como en otro, mantiene más discrepancias que coincidencias. Arconada contrapone el idealismo del caballero andante con el carácter analítico de su prosa. Tampoco se identifica con el sentimiento trágico de Unamuno, pues considera que este impide a la literatura ser un testimonio de denuncia. Asimismo, como señala Santonja en el prólogo de Andanzas por la nueva China, la obra contiene, por un lado, alusiones al paisaje abandonado de España, como por ejemplo las tierras secas y el adobe de Castilla, y, por otro, referencias culturales a personajes literarios tales como el Cid Campeador, y escritores, entre ellos Blasco Ibáñez (Arconada, 2017: XVII-XXV).

El autor no se limita a relatar las experiencias del viaje como si de una crónica se tratase, ni tampoco describe espacios y personas tal cual se los presentan. Arconada plantea las vivencias como propias. Para ello, realiza una selección de contenidos los cuales narra sin omitir su punto de vista. Esta técnica permite al narrador, en cierto modo, burlar de la visión oficial de los hechos.

El matrimonio Arconada comienza el viaje en agosto de 1957 en Sian, acompañado en todo momento por personal del Partido Comunista. Durante el recorrido visitan los locales del partido y otras instituciones como la Unión de Escritores en Nankín y de Sian. También políticos, comerciantes y artistas reciben a la pareja como, por ejemplo, el poeta Ban Lao-tsiu:

Miembro de la Unión de Escritores de la China, de la junta directiva de la Asociación de Amistad China-Unión Soviética, del Consejo Político Consultivo de la provincia, de la Asociación de Trabajadores de Literatura y Arte y, por último, propagandista en su aldea (Arconada, 2017: 191).

En Sian, los Arconada están interesados en visitar Yenán, un lugar no incluido en la ruta y al que los organizadores no eran partidarios de desplazarse, argumentando dificultades de acceso. A diferencia de los Alberti, la pareja quiere hacer algunas modificaciones sobre el viaje 
propuesto. Estas son aceptadas, aunque el equipo organizador intenta seguir la planificación.

El viaje continúa hacia Pekín, que el autor describe como un lugar armonioso, Nankín y Shanghai, considerada esta última por Arconada como "una hirviente ciudad que laboran para la grandeza de su patria y para el bienestar de ellos mismos" (123), es decir, donde la política económica prescinde de capital extranjero y no está en manos de colonos:

Shangai, el centro industrial y comercial más grande del país, fue una de las primeras ciudades donde resonaron los estridentes platillos del júbilo y aparecieron por la calle los danzantes dragones: toda la industria y el comercio de la ciudad pasaba a tomar un carácter socialista. Las industrias y los comercios particulares [...] se transformaban en empresas mixtas de particulares y del estado (123).

Arconada hace algunos comentarios sobre la Guerra Civil con los japoneses y la invasión de estos:

Frecuentemente los japoneses hacían incursiones por la provincia para rapiñar lo que pudieran, hacer daño por todas partes y sembrar el dolor a diestra y siniestra. Tenían especial inquina a los maestros: como todos los invasores, se mofaban del que enseñaba, temiendo que enseñase a odiarlos (181).

Como en otras ocasiones, el autor establece paragones ente la historia china y la española. El viaje estaba pensado para visitar las cooperativas y ensalzar la ferviente producción industrial del momento, es decir, la modernidad que triunfaba sobre los viejos modos de producción. El autor hace hincapié en la relación del hombre con un determinado modo de producción. Arconada ve en la industrialización la idea de progreso. El autor emplea un estilo personal, en el sentido en que en ocasiones sale de la función de narrador para opinar sobre cuanto observa, mientras hace de intermediario entre escritor y lector.

La siguiente parada en el viaje es Hangchow, que considera como una ciudad de leyenda y, ya en Pekín, hace una extensión a Cantón, antes de concluir el viaje.

El autor parte de la base de que el presente refunda la historia. Por ello, partiendo de un tiempo presente se adentra en el pasado a través de historias o de un abanico de tradiciones. En la descripción del viaje está 
presente la artesanía, las técnicas agrícolas con cultivos tan importantes como el arroz, las referencias gastronómicas, las danzas y leyendas. Los lugares de interés patrimonial, como es el caso de la Ciudad Sagrada, los relaciona con la historia y la sociedad del momento. Así pues, desde el presente rememora los tiempos en que algunas ciudades de China fueron cruce de caminos de rutas comerciales. Este es el caso de Yenán que:

esa situación privilegiada, de borde de ruta, de venta de camino entre Oriente y Occidente, y entre China y la India, es lo que hizo que de Sian la capital de once antiguas dinastías (175).

También, observando una fábrica textil, recuerda la tradicional producción de seda:

[Sian] ciudad famosa por sus sedas, cuya fabricación se remonta a tiempos antiguos, cuando por el canal y el río Huang He salían a Europa, por la llamada Ruta de la Seda, los tejidos de abigarrados colores que aquí se fabricaban. (148)

Cuando Arconada visita China ya no quedan talleres artesanales, sino que las ciudades con experiencia textil estaban pobladas de fábricas, totalmente mecanizadas, con centenares de empleadas y un aumento vertiginoso de producción gracias a los planes de desarrollo industrial.

Como M. ${ }^{\text {a }}$ Teresa León en Andanzas por la nueva China, Arconada relata el día a día de una mujer y su presencia en los cambios que acontecen. Para el autor, el estatus que ha conseguido la mujer en la República Popular de China es un signo de recuperación económica y de integración social. Este logro le produce nostalgia al recordar las mejoras sociales de la mujer en España, conseguidas en los años treinta y abortadas con la contienda bélica:

Miro, remiro y miro a esta mujer, y me recuerda a muchas mujeres jóvenes de la nueva China. Al verlas, parece que no son nada: una de tantas entre tantas. Pero en cambio han pasado por las llamas de muchas hogueras, forjándose en ellas y preparándose para ser rectoras de asuntos públicos y comisarias de las almas de la gente sencilla (Arconada, 2017: 185). 
En definitiva, Arconada elogia el sistema político cuando dice: "¡Gloria al Partido Comunista Chino!" (28). Todo ello con un sentimiento de nostalgia que articulan la narratio de la obra que le sirve de canal para expresar el desarraigo y mostrar su postura disidente con la realidad política española.

\section{La literatura y el Paisaje Cultural}

Tras lo anteriormente expuesto, comprobamos que M. ${ }^{\mathrm{a}}$ Teresa León y Rafael Alberti, así como César M. Arconada, describen los paisajes con la ayuda de elementos físicos y testimonios orales -aunque buena parte estén condicionados por la consigna propagandística-e informaciones de índole histórica, geográfica, social o etnográfica. A estos elementos, cada autor, en función de su retórica particular y del periodo artístico, añade elementos con criterio propio que conducen a una interpretación personal y subjetiva. Si, además, tenemos en cuenta que la situación de estos autores es la de exiliados, las emociones propias de esta condición juegan un papel primordial en la configuración del paisaje.

El recorrido por la China de Mao les lleva a conocer ciudades, algunas de ellas patrimoniales, que han pasado de tener un tamaño reducido a estar en proceso de convertirse en metrópolis. Ello implica cambios considerables en el paisaje tradicional. Una situación similar sucede con las poblaciones rurales que amplían sus dimensiones o son testigos de un éxodo rural y hacen peligrar la permanencia de algunas tradiciones ancestrales.

La construcción literaria de este mosaico de paisajes y el testimonio de los cambios gestados a todos los niveles en el país desde la Revolución Comunista aportan a los dos relatos de viajes un interés como material de análisis de un paisaje cultural y sugieren un posicionamiento metodológico para el análisis de ambas obras literarias.

El Paisaje Cultural se compone de una red de variantes, fijas y mutantes, materiales e inmateriales, que con el paso del tiempo conforman una identidad. Es decir, un espacio donde la acción humana modifica y deja huella en la naturaleza que sucesivamente encuentra una generación tras otra (Giusti y Romeo, 2010: 5-7, 21). En este contexto, Giusti habla de Paisajes de Artistas para definir una tipología según la cual: 
... vive attraverso l'immaginario mondo di artisti, poeti, letterati; metafore di luoghi e situazioni, di incontri e condivisioni, paesaggi altri che intercettano luoghi fisici, incrementandone i valori educativi (2010: 91-96).

Con todo ello, quedan definidos los paisajes en que los escritores conjugan sus experiencias reales con el mundo imaginario, este último condicionado por la cultura previa y las condiciones anímicas del autor. En este sentido, las fuentes literarias, inmateriales y no exentas de subjetividad, suponen una fuente de conocimientos y una pluralidad de informaciones que complementan el estudio de una realidad.

Para el estudio de estas obras desde el posicionamiento metodológico indicado, es preciso determinar su contextualización. Sonríe China y Andanzas por la nueva China se centran en los cincuenta. Esta década representa para China un periodo bisagra, ya que abandona las estructuras de la China Imperial para dar paso a los cambios de la Revolución Comunista que supera el orden político. Un año después de los viajes de estos escritores españoles, Mao lanzó el Gran Salto Adelante que consistió en un proyecto económico que promovió el desarrollo de la industria pesada y la colectivización de la producción agrícola.

En la mirada literaria, los autores relacionan la situación del momento con la historia que acompaña a los lugares que visitan de esta civilización milenaria. Siete décadas más tarde, algunos de los lugares que recorren estos autores (véase mapas adjuntos) forman parte de itinerarios culturales como, por ejemplo: la Ruta de la Seda. Otros lugares, integrados o no en este itinerario, han sido declarados patrimonio cultural por la Unesco, como sería el caso de la Gran Muralla China. En este sentido, la aportación literaria contribuye a la materialización del Paisaje Cultural ya que el escritor deja testimonio de un momento concreto y, quizás lo más importante, la percepción que un viajero percibe del paisaje, de lo cotidiano y la memoria del trabajo y del lugar.

Pongamos el ejemplo de la producción de la seda y su presencia en las obras de estudio. Este producto icono de China, forma parte de la historia del país y será, en sentido figurativo, el hilo cohesionador de actividades y espacios descritos. Cuando los autores españoles visitan China en 1957, la actividad de la seda, así como toda la industria textil, vive una revolución tecnológica. Si China había sido el país que había 
comenzado con la producción artesanal de este producto, siglos más tarde será pionera en la producción industrial de los tejidos ${ }^{16}$.

César Arconada nombra algunos lugares donde la actividad textil está transformando la economía de la zona. Como sus compatriotas, dedica un espacio importante de su relato a la formación de cooperativas y a las condiciones de sus trabajadores. Su adhesión a la ideología comunista y la impresión de estar en un país en vías de desarrollo le aporta un optimismo que contrasta con el pesimismo que proyecta en sus recuerdos a España ${ }^{17}$.

El propio autor interviene de forma directa en la configuración del paisaje cultural, pues a través de un proceso sensitivo escoge los elementos que más centran su atención y su filiación estética determina la construcción literaria del paisaje. Es decir, el autor es un agente más en la construcción del paisaje cultural.

En el caso concreto de la Ruta de la Seda, el hecho de ser declarada Patrimonio de la Humanidad favorece la puesta en valor de todos los recursos que componen un paisaje cultural, entre los cuales se encuentran las fuentes literarias.

En resumen, estos viajes intelectuales estrechan la relación entre geografía, paisaje y literatura, y se construyen desde un entramado de diferentes áreas de conocimiento que supone una transferencia de conocimientos necesaria para la construcción de un paisaje cultural.

\section{Conclusiones}

Ambas obras se construyen con una intención descriptiva y con reflexiones personales, un planteamiento recurrente en la literatura de viajes. Sin embargo, la realidad específica de sus autores está supeditada a la condición de exiliados. Una situación que les lleva a representar

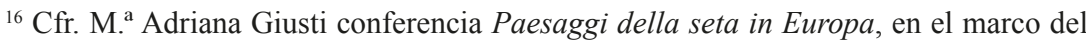
II Encuentro "La Ruta de la Seda en la Universitat de València". Valencia, 15 de diciembre de 2017.

${ }^{17}$ Téngase en cuenta que en este mismo periodo España, a través de diferentes planes internacionales de ayuda y de iniciativas gubernamentales, ha salido de la autarquía de los años cuarenta. En este periodo, las grandes ciudades se están industrializando y el éxodo rural es el paisaje humano de la España del momento. Sin embargo, los intelectuales exiliados viven estos cambios con escepticismo ya que ello no implica la abolición de la Dictadura.
} 
un abanico de emociones variadas, tales como desamparo y desarraigo. Asimismo, las circunstancias determinadas de estos exiliados les llevan a mantener un compromiso político expresado en su literatura; sus textos dejan filtrar numerosas muestras de disidencia que encuentran su cauce en la libertad de expresión que tienen en los países de acogida. Por otro lado, las circunstancias particulares de los autores exiliados de la Edad de Plata y de sus respectivas influencias literarias les condicionan la observación de la cultura ajena.

Los tres autores estudiados tienen una percepción espacial subjetiva y muestran una mayor filiación estética con el Grupo del 98 y con el modernismo literario que con las corrientes realistas de la época que emplean sus compatriotas que permanecen en España.

Estos itinerarios ponen en valor la literatura y, en concreto, el género de viajes al aportar una transferencia de conocimientos. Más allá de exponer las reflexiones de los autores, Andanzas por la nueva China y Sonrie China contribuyen a ampliar el imaginario sobre el país a nivel geográfico y cultural. La pluralidad de informaciones del presente y del pasado permite interrelacionar varios aspectos de la sociedad china $\mathrm{y}$, a la vez, la creación de un paisaje cultural.

\section{Bibliografía}

Alberti, Rafael. 1975. La arboleda perdida (2 vol.). Barcelona: Seix Barral. Alberti, Rafael \& León, M. ${ }^{a}$ Teresa. 1958. Sonríe China. Buenos Aires: Muchnik.

Alburquerque García, Luis. 2011. "El relato de viajes": hitos y formas en la evolución del género. Revista de literatura 73(145): 15-34.

Arconada, César M. 2017. Andanzas por la nueva China. Madrid: Fundación Banco Santander.

Bayo, Manuel. 1990. China en la literatura española contemporánea. Encuentros en Cathay 4: 51-135.

Carrizo Rueda, Sofía. 1997. Poética del relato de viajes. Kassel: Reichenberger.

Díez de Revenga, Francisco Javier. 2004. Las vanguardias y la Generación del 27. Madrid: Síntesis.

Esteban, José \& Santonja, Gonzalo. 1988. Los novelistas sociales españoles (1928-1936). Antología. Barcelona: Ánthropos.

Garrido Gallardo, Miguel Ángel. 1998. La noción de género literario en el siglo XX. En García Antón, Cecilia \& Torres Martínez, José Carlos de (ed.) Estudios de Literatura Española de los siglos XIX y XX: Homenaje a Juan María Díez Taboada. Madrid: CSIC, 869-874. 
Giusti, Maria Adriana \& Romeo, Emanuele, 2010. Paesaggi culturali / Cultural Landscape. Roma: Aracne Editrice.

Hernández Fernández, María Teresa. El imaginario oriental de Alberti y Neruda. Epos: Revista de filología 2: 139-155.

Lechner, Johannes. 1969. El compromiso en la poesía española del siglo XX (2 vol.). Leiden: Universitaire Pers Leiden.

León, María Teresa. 1998. Memoria de la melancolía. Madrid: Castalia.

Mainer, José Carlos. 1981. La Edad de Plata, 1902-1931. Madrid: Cátedra.

Ollé Rodríguez, Manel. 1998. La invención de China. Mitos y escenarios de la imagen ibérica de China en el siglo XVI. Revista Española del Pacífico 8: $541-568$.

Ortega Cantero, Nicolás. 1987. Geografia y cultura. Madrid: Alianza.

Juliá, Santos. 2004. Rafael Alberti: Un intelectual en política. En Santonja, Gonzalo (ed.) El color de la poesía (Rafael Alberti en su siglo) I. Madrid: Sociedad Estatal de Conmemoraciones culturales, 203-223.

Sanz Villanueva, Santos. 1980. Historia de la novela social española: 19421975 (2 vol.). Madrid: Alhambra.

Taillot, Allison. 2012. A prueba del tiempo: las intelectuales antifascistas españolas entre silencio oficial y lucha por la memoria. Historia Actual Online 19: 29-39. http://historia-actual.org/Publicaciones/index.php/ hao/article/view/296 [Acceso 28/03/2018].

Taillot, Allison. El modelo soviético en los años 1930: los viajes de María Teresa León y Rafael Alberti a Moscú. Cahiers de civilisation espagnole contemporaine 9. http://ccec.revues.org/4259 [Acceso 24/03/2018].

Tejada, José Luís. 1977. Rafael Alberti: entre la tradición y la vanguardia. Madrid: Gredos.

Torres Nebrera, Gregorio. 1992. María Teresa León. Los espacios de la memoria. Draco: revista de literatura española 3-4: 349-385.

Torres Nebrera, Gregorio. 2004. Sonríe China: memoria de un libro compartido. En Salaün, Serge \& Carandell, Zoraida (ed.) Rafaël Alberti et les avant-gardes. Paris: Presses Sorbonne Nouvelle, 291-303.

Vila, José Antonio. 2017. Los intelectuales, el compromiso y el medio siglo español. Artes del ensayo 1: 140-152.

Vilagrasa, Joan. 1988. Novela, espacio y paisaje: sugerencias para una geosofía estética. Estudios geográficos 49(191): 271-286. 